\title{
Improving Cardiovascular Health Among African-Americans Through Mobile Health: the FAITH! App Pilot Study
}

\author{
LaPrincess C. Brewer, MD, MPH', Sharonne N. Hayes, $M D^{7}$, Sarah M. Jenkins, $M S^{2}$, \\ Kandace A. Lackore, BA ${ }^{2}$, Carmen Radecki Breitkopf, PhD ${ }^{3}$, Lisa A. Cooper, MD, MPH ${ }^{4,5}$, and \\ Christi A. Patten, PhD $^{6}$
}

\begin{abstract}
'Department of Cardiovascular Medicine, Mayo Clinic, Rochester, MN, USA; ${ }^{2}$ Division of Biomedical Statistics and Informatics, Mayo Clinic, Rochester, MN, USA; ${ }^{3}$ Division of Health Care Policy and Research, Mayo Clinic, Rochester, MN, USA; ${ }^{4}$ Department of Medicine, Johns Hopkins School of Medicine, Baltimore, MD, USA; ${ }^{5}$ epartment of Health, Behavior and Society, Johns Hopkins Bloomberg School of Public Health, Baltimore, MD, USA; 'Department of Psychiatry and Psychology, Mayo Clinic, Rochester, MN, USA.
\end{abstract}

KEY WORDS: cardiovascular disease; community-based interventions; community-based participatory research (CBPR); disparities; health promotion; minority health.

$\begin{array}{ll}\text { Abbreviations } \\ \text { AA } & \text { African-American } \\ \text { AHA } & \text { American Heart Association } \\ \text { BMI } & \text { Body mass index } \\ \text { BP } & \text { Blood pressure } \\ \text { CBPR } & \text { Community-based participatory research } \\ \text { CV } & \text { Cardiovascular } \\ \text { FAITH! } & \text { Fostering African-American Improvement in Total } \\ & \text { Health } \\ \text { LS7 } & \text { Life's Simple 7 } \\ \text { mHealth } & \text { Mobile health } \\ \text { NHANES } & \text { National Health and Nutrition Examination Survey } \\ \text { PA } & \text { Physical activity }\end{array}$

J Gen Intern Med 34(8):1376-8

DOI: $10.1007 / \mathrm{s} 11606-019-04936-5$

(c) Society of General Internal Medicine 2019

\section{INTRODUCTION}

African-Americans (AAs) have $82 \%$ lower odds than whites of meeting five or more ideal cardiovascular (CV) health components comprising the American Heart Association (AHA) Life's Simple 7 (LS7), an evidence-based metric of seven healthpromoting behaviors and biologic factors that, at ideal levels, improve CV outcomes (diet, physical activity [PA], cigarette smoking, body mass index [BMI], blood pressure [BP], total cholesterol, fasting glucose). ${ }^{1}$ Mobile health (mHealth) interventions are promising for promoting $\mathrm{CV}$ health within this population. ${ }^{2}$ Culturally relevant health interventions delivered through community-based participatory research (CBPR) approaches have proven successful in substantially impacting specific CV

Prior Presentations Preliminary findings of this study were presented at the annual meeting of the American Heart Association Epidemiology and Prevention Lifestyle Scientific Sessions, New Orleans, LA, March 20-23, 2018.

Published online March 18, 2019 risk factors (e.g., hypertension) in AAs. ${ }^{3}$ However, to our knowledge, our study is the first mHealth intervention targeting multiple risk factors by promoting ideal CV health (LS7) for AAs. We hypothesized that an evidence-based, theory-informed, culturally relevant, community-based mHealth lifestyle intervention would improve $\mathrm{CV}$ health among AA adults.

\section{METHODS}

The study was approved by the Mayo Clinic Institutional Review Board and registered (clinicaltrials.gov [NCT03084822]); participants provided written informed consent. Details on study rationale, recruitment procedures, and participant inclusion/exclusion criteria have been described. ${ }^{4}$ Briefly, we collaborated with five predominately AA churches in Minnesota using a CBPR approach to co-design a $\mathrm{CV}$ health and wellness digital applicationbased program (Fostering African-American Improvement in Total Health [FAITH!] App) as a translation from a previous inperson intervention to promote $\mathrm{CV}$ health. We enrolled $50 \mathrm{AA}$ adults from partnering churches with multiple $\mathrm{CV}$ risk factors into a single-group pilot study of a 10 -week intervention through the FAITH! App. The FAITH! App included 10 core multimedia education modules with videos from health professionals on $\mathrm{CV}$ health, interactive diet/PA self-monitoring, and social networking through a discussion/sharing board. Baseline data were collected in July 2016 and follow-up data at 28 weeks postintervention (April 2017) by trained research nursing staff at in-person health assessments and by self-administered electronic surveys. The primary outcome was change in $\mathrm{CV}$ health biologic factors (BP, total cholesterol, fasting glucose) and behaviors (diet, PA, cigarette smoking, BMI) from baseline to postintervention (28 weeks). Our secondary outcome was change after 28 weeks in LS7 composite score (calculated by summing scores of LS7 components by AHA-defined criteria: 2 points, ideal; 1 point, intermediate; 0 points, poor [range, $0-14$ points]; total score $\geq 9$, ideal). ${ }^{5}$ Paired outcomes were compared with Wilcoxon signed rank tests (ordinal or continuous variables) or McNemar tests 
Table 1 Sample Baseline Characteristics $(N=50)$

\begin{tabular}{|c|c|}
\hline Characteristic & No. $(\%)^{*}$ \\
\hline \multicolumn{2}{|l|}{ Sex } \\
\hline Male & $15(30.0)$ \\
\hline Female & $35(70.0)$ \\
\hline \multicolumn{2}{|l|}{ Age (years) } \\
\hline Mean (SD) & $49.6(12.7)$ \\
\hline \multicolumn{2}{|l|}{ Relationship status } \\
\hline Single & $9(18.0)$ \\
\hline Divorced & $7(14.0)$ \\
\hline Widowed & $2(4.0)$ \\
\hline Married or committed relationship & $32(64.0)$ \\
\hline \multicolumn{2}{|l|}{ Education level } \\
\hline High school graduate or less & $6(12.0)$ \\
\hline Some college & $12(24.0)$ \\
\hline Technical or Associate's degree & $11(22.0)$ \\
\hline College graduate or higher & $21(42.0)$ \\
\hline \multicolumn{2}{|l|}{ Employment status } \\
\hline Employed, at least part-time & $37(74.0)$ \\
\hline Unemployed & $9(18.0)$ \\
\hline Retired & $4(8.0)$ \\
\hline \multicolumn{2}{|l|}{ Annual household income } \\
\hline$<\$ 20,000$ & $5(11.1)$ \\
\hline$\$ 20,000-\$ 49,999$ & $19(42.2)$ \\
\hline$\$ 50,000-\$ 74,999$ & $9(20.0)$ \\
\hline$\geq \$ 75,000$ & $12(26.7)$ \\
\hline Chose not to disclose & 5 \\
\hline Health insurance & $48(96)$ \\
\hline \multicolumn{2}{|l|}{ Regular health care provider visits } \\
\hline Yes & $44(88)$ \\
\hline No & $6(12)$ \\
\hline \multicolumn{2}{|l|}{ Self-reported medical history } \\
\hline Overweight/obese & $31(62)$ \\
\hline Hypertension & $27(54)$ \\
\hline Type 2 diabetes mellitus & $10(20)$ \\
\hline Hyperlipidemia & $8(16)$ \\
\hline
\end{tabular}

*Unless otherwise indicated

(categorical variables). All analyses were conducted in 2017 with SAS version 9.3 (SAS Institute Inc.).

\section{RESULTS}

Participants' demographic characteristics are presented in Table 1 (70\% women [35/50]; mean [SD] age, 49.6 [12.7] years; 58\% < college-graduate education [29/50]). At baseline, $40 \%$ of participants had hypertension, $86 \%$ were overweight/ obese, and over $70 \%$ had poor/intermediate diet or PA. Study retention at 28 weeks was $98 \%$ (49/50). At 28 weeks, substantial improvements occurred in some $\mathrm{CV}$ health biologic factors (systolic BP, 133.3 to $127.1 \mathrm{mmHg}, P=.002$; diastolic BP, 82.8 to $77.1 \mathrm{mmHg}, P<.001$ ) and behaviors (diet, 3.4 to 4.5 fruit/vegetable servings/day, $P<.001$; moderate-intensity $\mathrm{PA}, 35$ to $75 \mathrm{~min} /$ week, $P=.04$ ). The LS7 composite score increased from 8.3 to 9.0 within the ideal $\mathrm{CV}$ health-score range $(P=.05)$ (Table 2$)$.

\section{DISCUSSION}

This small-scale, pre/post pilot study supports benefits of a culturally relevant, community-based mHealth lifestyle intervention for promoting CV health among AAs with high cardiometabolic risk. Recent analyses of National Health and Nutrition Examination Survey (NHANES) data show persistent CV health disparities by LS7 composite scores between whites and AAs and call for multifaceted, community-level interventions to curtail and eradicate these gaps. ${ }^{6}$ Our intervention, although a research prototype, offers an innovative medium to engage AA patients beyond office-based encounters through mobile technology with an overarching goal of diminishing CV disease risk and mortality.

Small sample size, no control group, relatively short study duration, and a convenience sample of predominantly women limit generalizability. Also, longitudinal data on health care utilization and medication adherence were not collected. However, our intervention had low attrition and several objectively measured positive outcomes for CV health, which are reflective of our formative work and prioritization of community engagement. A randomized controlled trial is planned to assess efficacy of the FAITH! App.

Table 2 Changes in Cardiovascular Health

\begin{tabular}{|c|c|c|c|}
\hline Variable* & Baseline & Postintervention & $P$ value \\
\hline \multicolumn{4}{|l|}{ Cardiovascular health factors } \\
\hline Systolic BP (mmHg) & $133.3(18.9)$ & $127.1(19.3)$ & .002 \\
\hline Diastolic BP (mmHg) & $82.8(10.3)$ & $77.1(12.0)$ & $<.001$ \\
\hline \multicolumn{4}{|l|}{ BP control } \\
\hline $\mathrm{BP}<140 / 90$, no. $(\%), \mathrm{mmHg}$ & $29(59.2)^{\dagger}$ & $40(81.6)^{\dagger}$ & .005 \\
\hline $\mathrm{BP}<130 / 80$, no. $(\%), \mathrm{mmHg}$ & $13(26.5)^{\dagger}$ & $23(46.9)^{\dagger}$ & .008 \\
\hline Total cholesterol $(\mathrm{mg} / \mathrm{dL})$ & $182.8(39.8)$ & $185.1(44.2)$ & .21 \\
\hline Fasting glucose $(\mathrm{mg} / \mathrm{dL})$ & $89.1(34.2)$ & $86.4(15.2)$ & .81 \\
\hline \multicolumn{4}{|l|}{ Cardiovascular health behaviors } \\
\hline Diet: fruit/vegetable intake, servings/day & $3.4(1.4)$ & $4.5(1.8)$ & $<.001$ \\
\hline Physical activity: moderate intensity, minutes/week, median, IQR & $35(0-110)$ & $75(25-188)$ & .04 \\
\hline Cigarette smoking status, current, no. (\%) & $1^{\S}(2.2)$ & $1^{\S}(2.2)$ & 1.0 \\
\hline BMI $\left(\mathrm{kg} / \mathrm{m}^{2}\right)$ & $33.1(7.3)$ & $33.0(7.1)$ & .48 \\
\hline Life's Simple 7 composite score & $8.3(2.2)$ & $9.0(2.1)$ & .05 \\
\hline
\end{tabular}

$B M I$, body mass index; $B P$, blood pressure; IQR, interquartile range

* Mean (SD) unless otherwise indicated

†Data missing for 1 patient

Adapted definition of diet from American Heart Association-defined healthy 5-component dietary pattern

${ }^{3}$ Data missing for 5 patients 


\section{CONCLUSIONS}

Culturally relevant, community-based mHealth interventions such as the FAITH! App may have potential to improve CV health among AAs.

Acknowledgments: We are indebted to all study participants and partnering church congregations for their unwavering passion and commitment to the design and implementation of the intervention and their valuable contributions to this research.

Corresponding Author: LaPrincess C. Brewer, MD, MPH; Department of Cardiovascular Medicine Mayo Clinic, 200 First St SW, Rochester, MN 55905, USA (e-mail: brewer.laprincess@mayo.edu).

Funders Dr. Brewer is supported by the Building Interdisciplinary Research Careers in Women's Health Scholars Program (award number K12 HD065987-07) from the National Institutes of Health (NIH) Office of Research on Women's Health, Mayo Clinic Women's Health Research Center, and the National Center for Advancing Translational Sciences (Clinical and Translational Science Awards Grant Number KL2 TR002379), a component of the NIH. This study was further supported by the Mayo Clinic Center for Innovation, Mayo Clinic Center for Translational Science Activities (UL1TR000135), Mayo Clinic Department of Cardiovascular Medicine, and Mayo Clinic Office of Health Disparities Research.

\section{Compliance with Ethical Standards:}

The study was approved by the Mayo Clinic Institutional Review Board and registered (clinicaltrials.gov [NCTO3084822]); participants provided written informed consent.

Conflict of Interest: The authors declare that they do not have a conflict of interest.
Disclaimer: The content is solely the responsibility of the authors and does not necessarily represent the official views of the NIH. The funding source had no role in the design and conduct of the study; collection, management, analysis, or interpretation of data; preparation, review, or approval of the manuscript; and the decision to submit the manuscript for publication.

\section{REFERENCES}

1. Bambs C, Kip KE, Dinga A, Mulukutla SR, Aiyer AN, Reis SE. Low prevalence of "ideal cardiovascular health" in a community-based population: the heart strategies concentrating on risk evaluation (Heart SCORE) study. Circulation. 2011;123:850-7.

2. Ray R, Sewell AA, Gilbert KL, Roberts JD. Missed opportunity? Leveraging mobile technology to reduce racial health disparities. J. Health Polit. Policy Law. 2017;42:901-24.

3. Victor RG, Lynch $\mathbf{K}, \mathbf{L i} \mathbf{N}$, et al. A cluster-randomized trial of bloodpressure reduction in Black barbershops. N. Engl. J. Med. 2018;378:1291-301.

4. Brewer LC, Jenkins $\mathbf{S}$, Lackore $\mathbf{K}$, et al. mHealth intervention promoting cardiovascular health among African-Americans: recruitment and baseline characteristics of a pilot study. JMIR Res Protoc. 2018;7:e31.

5. Thacker EL, Gillett SR, Wadley VG, et al. The American Heart Association Life's Simple 7 and incident cognitive impairment: The REasons for Geographic And Racial Differences in Stroke (REGARDS) study. J Am Heart Assoc. 2014;3:e000635.

6. Brown AF, Liang LJ, Vassar SD, et al. Trends in racial/ethnic and nativity disparities in cardiovascular health among adults without prevalent cardiovascular disease in the United States, 1988 to 2014. Ann. Intern. Med. 2018;168:541-9.

Publisher's Note Springer Nature remains neutral with regard to jurisdictional claims in published maps and institutional affiliations. 